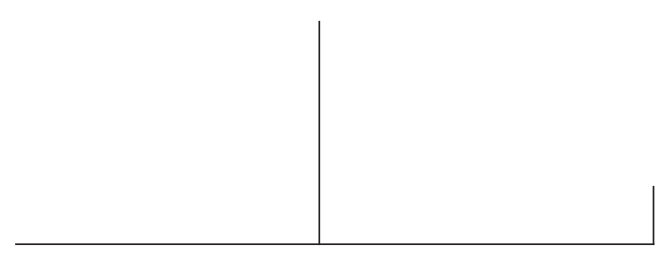

\title{
A psicopatologia na pós-modernidade* As alquimias no mal-estar da atualidade
}

\author{
Joel Birman
}

\begin{abstract}
A intenção deste estudo é a de circunscrever a especificidade da psicopatologia na pós-modernidade. Para isso, procura-se demonstrar as relações daquela com a medicina e as neurociências, assim como a sua recusa da psicanálise. Além disso, pretende-se mostrar como o interesse atual da psiquiatria nas pesquisas sobre as depressões, as toxicomanias e a síndrome do pânico pode ser interpretado a partir dos modelos de subjetividade promovidos pelo mundo pós-moderno.
\end{abstract}

* Conferência realizada em Paris, na instituição La Psychanalyse Actuelle, em 5 de fevereiro de 1998. 


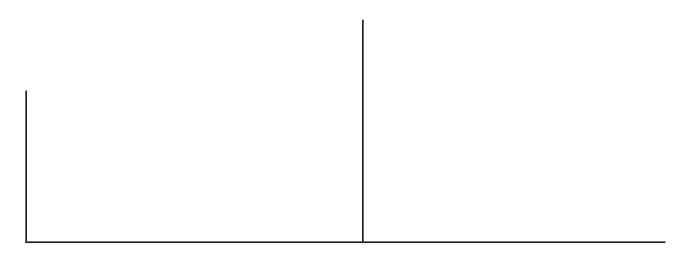

\section{A clínica na atualidade}

Se examinarmos, até mesmo sem muito cuidado, as publicações recentes dos campos da psicopatologia e da psiquiatria clínica, pode-se reconhecer certas características bem particulares. Trata-se de uma velha e antiga psicopatologia, por um lado, e de uma nova psicopatologia, em contrapartida, pelo outro. É bom que se diga, logo no início, que as idéias de novidade e de antiguidade devem ser consideradas aqui de uma maneira totalmente contextual e conjuntural. Contudo, o fato de sublinhar a relevância do contexto e da conjuntura não se opõe ao relevo que se confere à idéia de história, isto é, a uma leitura histórica dos discursos psicopatológico e psiquiátrico. Ao contrário, as noções de contexto e de conjuntura apenas podem ser bem apreendidas quando inscritas na trama de uma temporalidade histórica, à medida que apenas assim a especificidade do discurso psicopatológico atual pode ser bem evidenciado. É necessário, pois, circunscrever devidamente este campo, porque a nitidez e a consistência da interpretação que será aqui avançada e proposta estão na dependência estrita desta delimitação teórica e histórica.

Vamos delinear aqui, então, este campo atual da psicopatologia, sublinhando aquilo que é valorizado no registro das publicações especializadas, antes de mais nada. Estou me referindo às publicações advindas dos mundos anglo-saxônico e brasileiro, mas acredito, pela pesquisa que realizei, que o mesmo se possa dizer da psicopatologia francesa. Assim, o que se pode depreender da leitura, mesmo superficial, das revistas especializadas?

Antes de mais nada, as publicações são centradas em três enfermidades, ou síndromes, como vocês quiserem nomear tais perturbações do espírito, 


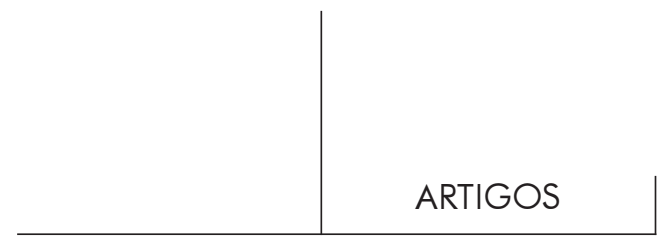

que dominam o espaço destas revistas e a preocupação de seus editores. Assim, o que os periódicos valorizam sempre, de maneira progressiva, são as depressões, as toxicomanias e a dita síndrome do pânico. Como se pode depreender, as duas primeiras foram anunciadas no plural e a última no singular, por razões que ainda comentaremos adiante. Independente disso, contudo, existe uma estranha preocupação dos pesquisadores com estas perturbações psíquicas, de uma maneira bastante específica.

É preciso recordar, no entanto, por uma questão de respeito e até reconhecimento pela verdade histórica, que o interesse da psiquiatria e da psicopatologia por estas perturbações do espírito é apenas recente e pontual. Este não é o caso, absolutamente. Trata-se de um processo histórico iniciado já há vinte anos mais ou menos. Desde o final dos anos 70 podemos registrar a emergência destas preocupações teóricas na literatura especializada. Além disso, não pretendo afirmar, bem-entendido, que o interesse particular da psicopatologia naquelas perturbações psíquicas, implique num silêncio absoluto em relação às outras perturbações do campo psiquiátrico. Não se trata disso. Porém, o investimento do discurso psicopatológico nestas outras perturbações é não apenas menor em relação ao passado psiquiátrico, mas também bem menor em relação às depressões, às toxicomanias e à síndrome do pânico. É no campo deste duplo relativismo que é preciso empreender o interesse da atual psicopatologia nestas três formas de perturbação do espírito, o que evidencia devidamente a dimensão histórica do dispositivo psiquiátrico em questão.

É preciso reconhecer, em seguida, que não é evidente o interesse revelado pela psicopatologia por tais perturbações mentais. Isso é óbvio, venhamos e convenhamos. Porém, isso precisa ser não apenas mostrado, mas também demonstrado. De qualquer maneira, é preciso dar lugar ao espanto que este interesse provoca, para que se possa interpretar a sua construção histórica. Com efeito, pode-se até mesmo afirmar que existe algo de estranho e de enigmático nestas escolhas da psicopatologia recente. Tudo isso é bastante espantoso, seguramente.

Por que afirmo isso?

\section{Enigmas?}

Antes de mais nada, não se pode dizer que o interesse da psicopatologia por aquelas perturbações mentais seja uma decorrência direta do aumento destas, no sentido estritamente epidemiológico. Não se trata disso. Com efeito, não existe um aumento daquelas perturbações de uma maneira homogênea. Pode-se afirmar seguramente que existe, no Ocidente, um crescimento significativo das toxicomanias nas últimas décadas. Além disso, se constituíram novas modalidades de toxicomanias, anteriormente inexistentes. Isso é perfeitamente constatável pelas 


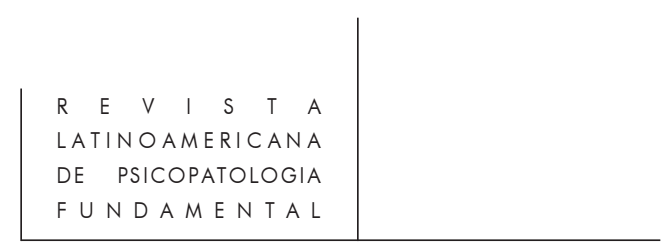

pesquisas epidemiológicas e pela experiência clínica. Em contrapartida, o mesmo não acontece nem com as depressões nem com a síndrome do pânico. Existe, pois, uma assimetria evidente, do estrito ponto de vista epidemiológico, entre as toxicomanias e as depressões e a síndrome do pânico, à medida que as primeiras aumentam de forma significativa e o mesmo não se pode dizer das demais.

A questão que se levanta aqui é, para mim, evidente. Por que as pesquisas psiquiátricas investem tanto nestas três modalidades clínicas de perturbações do espírito, quando apenas as toxicomanias revelam uma transformação significativa de suas taxas de incidência e de prevalência? Evidencia-se com isso, então, um registro inicial, para o meu espanto, com as escolhas empreendidas pelo discurso psicopatológico.

Em seguida, a outra questão que levanto aqui, sobre isso, é a da repetição em série destas três perturbações do espírito no discurso psicopatológico. Vale dizer, estas diferentes perturbações aparecem sempre como um conjunto, no contexto das publicações especializadas e no imaginário atual da psicopatologia. Isso também não é evidente, absolutamente, para mim. A indagação que coloco aqui, pois, concerne agora à relação imaginária que foi estabelecida entre estas três perturbações do espírito. Isso porque existe uma relação secreta e enigmática entre estas diferentes formas de perturbações psíquicas, que não é algo óbvio ao nível da descrição clínica e psicopatológica. Com efeito, a fenomenologia clínica destas perturbações não permite e não autoriza esta aproximação e esta seriação.

O que implica em afirmar que é preciso uma operação de deciframento para que se possa dar conta desta repetição em série e da configuração deste conjunto psicopatológico, pois nada as reúne do ponto de vista estritamente clínico. Devese perguntar agora, se não existiria uma articulação interna entre estas três formas de perturbação mental, algo a ser evidenciado, que não é absolutamente claro no registro das descrições clínicas e fenomenológica de seus sintomas. Procurar responder a isso, de uma forma ao mesmo tempo consistente e legítima, será a minha segunda questão neste artigo.

Porém, para que o deciframento deste enigma e da relação nebulosa entre estas perturbações do espírito possa se realizar, é preciso anunciar os traços epistemológicos do novo discurso psicopatológico. É o que farei em seguida.

\section{O paradigma das neurociências}

Assim, uma terceira característica da psicopatologia atual é a sua pretensão em ter um fundamento biológico. A biologia é o fundamento incontestável da psicopatologia na atualidade. As neurociências fornecem os instrumentos teóricos 


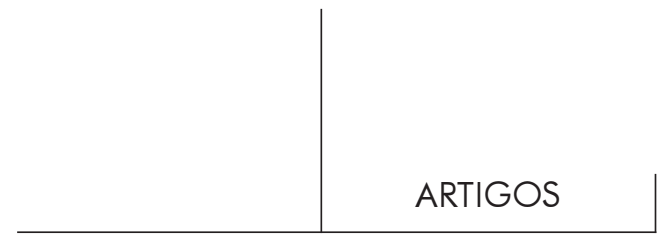

que orientam a construção da explicação psiquiátrica. Por este viés, pois, a psicopatologia pretende ter encontrado finalmente a sua cientificidade, de fato e de direito. Além disso, a nova psicopatologia acredita ter se encontrado enfim com a sua vocação médica, num processo iniciado no início do século XIX, à medida que se fundaria no discurso biológico.

Como se sabe, a psiquiatria sempre se encontrou numa posição incômoda no campo da medicina, pois pretendendo ser uma especialidade médica nunca conseguiu se fundamentar com os saberes advindos da racionalidade médica. $\mathrm{O}$ discurso do anátomo-clínica, ${ }^{1}$ base epistemológica da dita medicina científica, não encontrava legitimidade no campo da psiquiatria. ${ }^{2}$ A psiquiatria buscava as causas físicas dos distúrbios mentais e apenas encontrava, desde Pinel e Esquirol, as causas morais. Em contrapartida, o tratamento moral era a base da terapêutica psiquiátrica - em níveis individual e institucional -, que se afastava então de maneira decisiva dos cânones do saber médico. ${ }^{3}$ Enfim, a psiquiatria era uma falsa medicina, uma pseudo-medicina, já que não se fundamentava pelos saberes que fundavam a medicina.

A psicofarmacologia possibilitou, desde os anos cinquienta, a construção de uma outra identidade para a psiquiatria, que pôde se aproximar, então, dos cânones da medicina. O desenvolvimento recente das neurociências possibilitou a reconstrução da medicina mental, aproximando esta, finalmente, da medicina somática. Completou-se, com isso, o sonho do saber psiquiátrico de se transformar não apenas numa ciência, mas numa especialidade médica.

Pode-se depreender disso o que existe de antigo e de novo na psicopatologia da atualidade, como afirmei inicialmente. Com efeito, ao se fundamentar no discurso das neurociências, a psicopatologia consegue se realizar como uma modalidade de saber médico, se encontrando com a sua antiga pretensão originária de pertencer ao campo da medicina. Nada mais antigo, pois, que a novidade apresentada pela psicopatologia contemporânea, que encontra finalmente as suas origens e seus mitos fundadores, legitimando a sua identidade médica.

Ao se fundamentar nos discursos das neurociências a psicopatologia atual pôde questionar a causalidade moral das perturbações do espírito, para nos valermos da linguagem do discurso psiquiátrico originário, ${ }^{4}$ onde se opunham as causas morais e físicas das perturbações mentais. Isso porque as neurociências

1. M. Foucault. Naissance de la clinique. Une archéologie du regard medical. Paris, Presses Universitaires de France, 1963.

2. M. Foucault. Histoire de la folie à l'âge classique. Paris, Gallimard, 1972.

3. J. Birman. A psiquiatria como discurso da moralidade. Rio de Janeiro, Graal, 1978.

4. Sobre isso, vide J.E.D. Esquirol. Des maladies mentales. Volumes I e II. Paris, J.B. Baillière, 1838. 


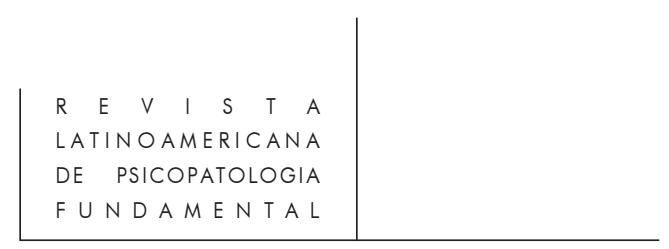

têm a pretensão de fundamentar as funções do espírito, de maneira autônoma e independente. Vale dizer, as neurociências pretendem construir uma leitura do psiquismo, de base inteiramente biológica. Com isso, o funcionamento psíquico seria redutível ao funcionamento cerebral, sendo este representado numa linguagem bioquímica. Enfim, a economia bioquímica dos neurotransmissores poderia explicar as particularidades do psiquismo e da subjetividade.

Esta transformação epistemológica produziu mudanças terapêuticas imediatas. A psicofarmacologia se transformou no referencial fundamental da terapêutica psiquiátrica, dado que as neurociências pretenderam fundar uma leitura do psiquismo. Com isso, a medicação psicofarmacológica pretende ser a modalidade essencial da intervenção psiquiátrica. Em consequiência disso, a psicoterapia tende a ser eliminada do dispositivo psiquiátrico, transformando-se num instrumento totalmente secundário face à intervenção psicofarmacológica. A psicoterapia passa a ser representada como uma peça de museu, sendo colocada como periférica no dispositivo psiquiátrico da atualidade.

Com este deslocamento das psicoterapias para a periferia da intervenção psiquiátrica se constituiu uma inversão significativa entre a psicanálise e a psiquiatria, como veremos agora.

\section{Inversões}

Assim, pela pretensão realizada de ter se transformado numa "ciência" e numa especialidade médica "respeitável", a psiquiatria não quer ter mais qualquer proximidade com a psicanálise. Seria preciso afastar a psicanálise do campo psiquiátrico, não misturar mais, em qualquer hipótese, aquela com a psicopatologia, pois isso acarretaria o risco de afetar a identidade médica e "científica" da psiquiatria.

Aconteceu aqui algo espantoso, da perspectiva histórica. Diria mesmo surpreendente. E isso de um duplo ponto de vista, a serem considerados de maneira esquemática. Desta forma, poderemos aquilatar a inversão a que me referi acima.

Devemos evocar aqui, inicialmente, que até os anos 70 a psiquiatria era fundada no discurso psicanalítico. A psicanálise era o saber de referência fundamental da psiquiatria, não obstante o desenvolvimento progressivo da psicofarmacologia desde os anos 50. É evidente que já se constituíra então a oposição entre dois grandes paradigmas do campo da psicopatologia: o primeiro centrado na psicanálise e, o segundo, na psicofarmacologia. Contudo, o discurso psicanalítico ocupava uma posição estratégica no campo psiquiátrico, detendo a hegemonia no discurso psicopatológico. 


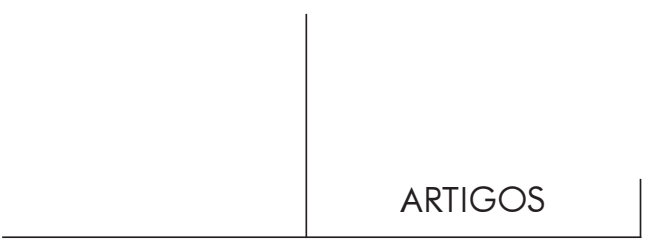

Com isso a psiquiatria era essencialmente psicanalítica, regulada que era pelos cânones psicanalíticos. Esta presença podia ser verificada tanto nas tradições francesa, quanto na inglesa e na norte-americana. Contudo, nos anos 70 tudo isso se transformou. O paradigma biológico da psiquiatria se impôs, reconstituindo o discurso psicopatológico em novas bases. Conseqüentemente, a psicanálise perdeu o lugar de hegemonia no campo da psiquiatria, ficando, pois, numa posição secundária e subalterna.

Este processo histórico de reconstrução do campo psicopatológico já era evidente nos Estados Unidos no início dos anos 70, num processo irreversível iniciado nos anos $60 .^{5} \mathrm{Na}$ França, este processo de autonomização da psiquiatria face à psicanálise iniciou-se nos anos 80 e está em curso. No Brasil e na América Latina pode-se reconhecer o mesmo rumo nas novas relações entre a psiquiatria e a psicanálise.

Porém, todo este processo apresenta ainda uma outra face, que é tão fundamental quanto a primeira. Com efeito, a psicanálise não perdeu apenas a hegemonia no campo da psicopatologia, sendo substituída pelo paradigma biológico, mas, além disso, tem mostrado um interesse crescente pelos modelos biológicos das neurociências. Vale dizer, a psicanálise passa a incorporar no seu discurso os referenciais teóricos do discurso psiquiátrico. Tudo isso descaracteriza, evidentemente, o discurso psicanalítico.

Pode-se perceber isso não apenas no registro das novas publicações em psicanálise, como também nas linhas de pesquisa de laboratórios avançados de psicanálise na universidade. Isso se passa não apenas na Europa e nos Estados Unidos, como também na América Latina. A medicalização da psicanálise atingiu um outro limite, absolutamente novo, do que já conhecíamos de outros momentos da história do movimento psicanalítico.

Nesta inversão de lugares e de posições estratégicas, a psicanálise fica numa posição agora secundária no campo da psicopatologia. Além disso, o discurso psicanalítico começa a fazer bricolagens com os discursos das neurociências e do cognitivismo, silenciando a sua especificidade. A inversão, enfim, é total, no horizonte histórico que estamos inscritos, entre a psicanálise e a psiquiatria.

\section{Funcionalidades e acontecimentos}

É preciso sublinhar ainda a existência de uma outra característica da psicopatologia na atualidade, além das que foram já referidas. Este último

5. F. Castel, R. Castel, A. Lovell. La société psychiatrique avancée. Le modèle américain. Paris, Grasset, 1979. 


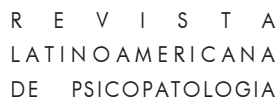

traço se articula de maneira serrada com o discurso terapêutico de base biológica.

Assim, a psicopatologia contemporânea se interessa fundamentalmente pelas síndromes e pelos sintomas, no sentido médico do termo. Com isso, a concepção tradicional de enfermidade, centrada na idéia de etiologia, perde terreno face à articulação de sintomas sob a forma de síndromes. Nestes termos, a psicopatologia da atualidade se aproxima bastante e até se identifica com a nova racionalidade clínica. Esta identificação não é arbitrária e casual, mas se realiza pela identidade da psiquiatria com o novo discurso da medicina clínica, que constituiu os parâmetros novos para realizar um outro recorte no universo das enfermidades.

Neste novo recorte, operado pela medicina clínica, é o medicamento, como instrumento supostamente "eficaz" sobre um conjunto articulado de sintomas, que passa a ser a referência maior para a nomeação e a construção da síndrome. A etiologia passa, neste novo contexto, a ocupar um lugar secundário. Os modernos textos de clínica médica desde os anos 70 e 80, são já construídos nesta moderna orientação metodológica. Enfim, as diferentes modalidades de malestar corpóreo são delineadas e classificadas como síndromes, se fundando para isso na ação terapêutica do medicamento, constituindo-se, pois, uma outra concepção nosográfica.

Tudo isso revela uma mudança da estratégica médica frente ao mal-estar corpóreo na sua diversidade. Não se pretende mais a cura, no sentido clássico da medicina clínica, mas apenas a regulação do mal-estar. Por isso mesmo, o medicamento se transforma no vetor da nova construção nosográfica, pois aquele seria o eixo da regulação corpórea. Revela-se, assim, que a leitura do mal-estar corporal assume uma direção totalmente funcional e não mais etiológica. Além disso, as dimensões da história do enfermo e do tempo da doença se transformam em questões secundárias diante do investimento que é realizado sobre o disfuncionamento corpóreo e espacial da enfermidade. Enfim, o novo discurso da medicina se centra sobre os acontecimentos corporais, marcados pela sua pontualidade temporal.

Poderíamos até, se quiserem, articular esta nova construção teórica da medicina com o sistema atual de cuidado e de assistência, no qual a regulação flexível dos disfuncionamentos corpóreos é totalmente dominante face não apenas ao diagnóstico mais conciso e profundo, mas também frente às terapêuticas etiológicas. Seria nestes termos, enfim, que a medicalização do social se realiza na atualidade.

Foi esta racionalidade funcional que a psicopatologia incorporou também no seu campo, de acordo com os parâmetros da racionalidade médica. É sempre a síndrome que está em questão, quando a psicopatologia se volta para a pesquisa 


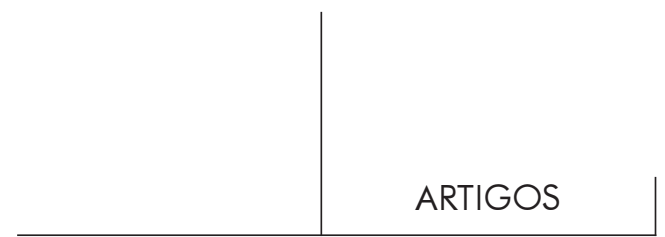

de diversas modalidades de depressão. Ou, então, quando se centra no estudo das fobias, renomeadas como síndrome do pânico. Da mesma forma, as toxicomanias são recortadas da mesma maneira, numa preocupação de ordem funcional.

Seria por isto que as depressões e as toxicomanias se enunciam no plural, à medida que revelam diversas ordenações funcionais, de acordo com os medicamentos escolhidos para a intervenção terapêutica. A antiga nosografia psiquiátrica se reconstitui então em novas bases.

Além disso, a forma de intervenção assume uma direção centrada em acontecimentos, nos quais se revelam os disfuncionamentos do psiquismo. A idéia de história de uma subjetividade, articulada com o eixo do tempo, tende ao silêncio e ao esquecimento. É sempre a pontualidade da intervenção, centrada no psicofármaco, o que está em questão na terapêutica do dispositivo psiquiátrico da atualidade.

\section{O espetáculo e o narcisismo}

Assim, pode-se dizer que a psicopatologia da dita pós-modernidade se caracteriza pelo paradigma biológico, onde as neurociências funcionam como sendo as referências teóricas daquela. Com isso, as psicoterapias ficam num plano secundário no campo da intervenção terapêutica, centrada substancialmente nos psicofármacos. Então a psicanálise passa a ocupar um lugar secundário e periférico no discurso psicopatológico atual. Além disso, as intervenções assumem uma incidência pontual, baseando-se em disfuncionamentos onde o registro das histórias dos sujeitos é algo absolutamente secundário.

Porém, após todo este percurso de caracterização da psicopatologia da pósmodernidade é preciso agora retomar o nosso ponto de partida, isto é, o fato de que neste campo psicopatológico se privilegiem as depressões, as toxicomanias e a síndrome do pânico. É sobre o enigma que isso tudo representa que devemos nos voltar agora.

Para realizar isso, em contrapartida, é preciso que desconfiemos, por pouco que seja, das evidências clínicas da psicopatologia. Vale dizer, como não se pode confiar inteiramente na cientificidade da psiquiatria, é preciso que nos indaguemos saber as supostas obviedades do consenso psicopatológico. Para isso, necessário é que nos perguntemos sobre a modalidade negativa de subjetividade que perpassa a leitura destas diferentes perturbações psíquicas, para que se possa surpreender qual é o estilo de sujeito que é positivamente destacado na atualidade. Vale dizer, é preciso caracterizar devidamente qual é o ideal de valores que deve pautar a forma de ser da individualidade no mundo pós-moderno. Quero dizer com isto 


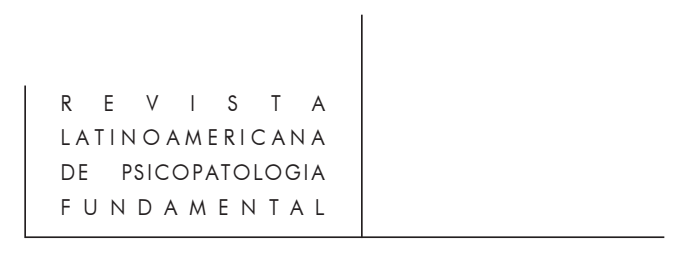

que as ênfases negativas colocadas na interpretação destas perturbações do espírito indicam o imperativo moral do que devemos ser. É justamente isto que nos cabe decifrar como enigma.

Como empreender isto? Para puxar o fio desta meada vou me valer das descrições, forjadas nos últimos anos, sobre a sociedade atual. Isto porque, nesse período, uma série de termos foi lançada no mercado de bens simbólicos com a finalidade de caracterizar as novas formas de sociabilidade que estavam se constituindo. Não tenho aqui a intenção de ser exaustivo, bem-entendido, mas de sublinhar somente algumas palavras deste vocabulário. É evidente que aquelas têm a pretensão de serem conceitos, isto é, de funcionarem como instrumentos operatórios capazes de desvelar a tessitura das novas modalidades de subjetividade.

Assim, no final dos anos 60, o autor francês G. Débord denominou de "sociedade do espetáculo" ${ }^{\circ}$ as modalidades originais de sociabilidade que então se forjavam, enquanto o norte-americano Lasch as interpretou segundo a lógica da "cultura do narcisismo" 7 , no final dos anos 70. Tudo isso pode ser considerado como variantes de uma mesma matriz, qual seja, o pós-modernismo. Pela concepção de pós-modernidade alguns teóricos procuraram enunciar um conceito genérico que fosse capaz de dar conta das sociabilidades inéditas que estavam se tecendo, indicando, com isso, uma ruptura com a modernidade.

Pode-se afirmar que, pela noção de sociedade do espetáculo, Débord indicara que a demanda de engendramento do espetacular definia o estilo de ser das individualidades e da relação entre essas na pós-modernidade. A idéia de espetáculo se conjuga aqui com as de exibição e de teatralidade, pelas quais os atores se inserem como personagens na cena social. Tratar-se-ia, antes de mais nada, de máscaras, mediante as quais as personas se inscrevem e desfilam no cenário social. Além disso, as metáforas do exibicionismo e da mise-en-scène reenviam para a de exterioridade, forma primordial pela qual se concebe a economia da subjetividade na sociedade do espetáculo. Tudo isso remete para as resultantes maiores desta leitura, isto é, a exaltação do eu e a estetização da existência realizadas pelos indivíduos.

Pelos imperativos da estetização da existência e de inflação do eu, pode-se fazer a costura entre as interpretações de Débord e de Lasch, já que a exigência de transformar os percalços incertos de uma vida numa obra de arte evidencia o narcisismo que o indivíduo deve cultivar na sociedade do espetáculo. Nesta medida, o sujeito é regulado pela performatividade mediante a qual compõe os gestos voltados para a sedução do outro. Este é apenas um objeto predatório

6. G. Débord. La societé du spetacle. Paris, Gallimard, 1994.

7. C. Lasch. The culture of narcissism. New York, Warner Bases Books, 1979. 


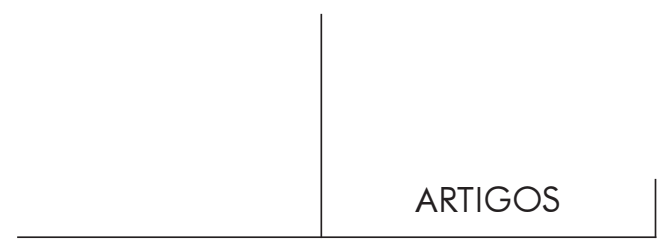

para o gozo daquele e para o enaltecimento do eu. As individualidades se transformam, pois, tendencialmente, em objetos descartáveis, como qualquer objeto vendido nos supermercados e cantado de prosa e verso pela retórica à publicidade. Pode-se depreender disso, com facilidade, que, neste contexto, a alteridade e a intersubjetividade são modalidades de existência que tendem ao silêncio e ao esvaziamento.

Toda esta construção, colorida pelos ouropéis do artifício, é mediada pelo universo da imagem. Esta é sempre a personagem principal que é valorizada e inscrita nos roteiros performáticos da pós-modernidade. A imagem é, pois, a condição sine qua non para o espetáculo na cena social e para a capitação narcísica do outro. A imagem é a condição de possibilidade da sedução e do fascínio, sem a qual o ideal de captura do outro não pode jamais se realizar neste festim diabólico de exibicionismo.

A produção deste imaginário social se realiza de diversas maneiras, entre as quais se destaca a mídia. Sem esta o espetáculo se esvazia, perdendo o seu colorido retumbante e o seu poder de captura do outro. Tanto pelas vias da televisão quanto da informática e do jornalismo escrito, a cena pública se desenha sempre pelas imagens. Desta maneira, não se pode mais opor o original e a cópia, pois o simulacro perpassa a totalidade do tecido social, constituindo uma nova concepção de realidade e do que seja o real.

Assim, ser e parecer se identificam absolutamente no discurso narcísico do espetáculo, sendo aquele o pressuposto ontológico desta interpretação da sociabilidade. Pela subversão das hierarquias entre o verdadeiro e o falso, do original e de suas cópias, a sociabilidade narcísica é antiplatônica por excelência. Com isso, o que o sujeito perde em interioridade ganha em exterioridade, de maneira que aquele é marcadamente autocentrado. É neste sentido que o sujeito se transforma numa máscara, para exterioridade, para a exibição fascinante e para a captura do outro.

\section{Dentro-de-si e fora-de-si}

Perde-se a densidade e a profundidade, transformando-se então o sujeito numa espécie de superfície plana, margeada pela moldura de um enquadre? É disso que se trata, afinal de contas? Transforma-se a cena do mundo num contraponto de reflexões especulares, onde a refração não perfura jamais o jogo encantado entre o olhar e o espelho? Rigorosamente falando, posso afirmar somente que eu não sei nada disso. São indagações legítimas que deve nos levar adiante, aprofundá-las, como questões cruciais que são, pelo trabalho do pensamento. 


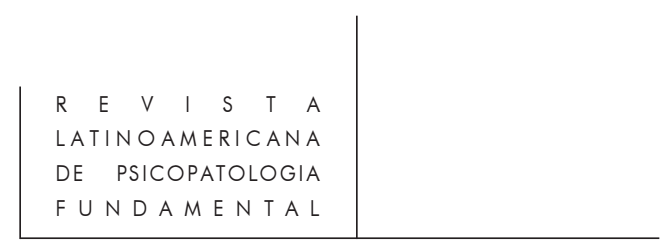

Contudo, de tudo isso algo de fundamental se destaca, que concerne à maneira pela qual a tradição ocidental representou a loucura, na sua matriz antropológica. Algo de original se anuncia aqui, indicando uma ruptura significativa com a representação da loucura iniciada no século XVI, que devemos ficar bem atentos.

O comentário que posso fazer sobre isso é que a concepção de sujeito forade-si - que no pensamento ocidental se identificou sempre com a loucura, numa longa tradição iniciada com Montaigne, passando por Descartes, Kant e Hegel recebe uma outra inflexão, plena de novidades para a reflexão teórica. Com efeito, o sujeito fora-de-si não se confunde mais, de maneira absoluta, com a concepção de alienação mental, tal como foi estabelecido pelo discurso psiquiátrico na aurora do século XIX. Isso porque o estar fora-de-si se identifica agora com a exterioridade da performance teatral, enjambrado que é o cenário da existência pelas lantejoulas e pelos coturnos que evidenciam o autocentramento da subjetividade. Porém, isso não é tudo. Além disso, é preciso evocar que se anteriormente o sujeito fora-de-si era representado de maneira absolutamente negativa, pois era, então, identificado apenas com a psicose e com a perda da razão, do eu e da interioridade, aquele é agora parcialmente concebido de maneira positiva, já que pelo autocentramento se dedica interminavelmente ao polimento de sua existência. Vale dizer, se dedica à sedução e ao fascínio do outro, pela mediação capturante das imagens exibidas na cena social.

Tudo isso tem conseqüências fundamentais na construção do discurso da psicopatologia na atualidade. Assim, se o sujeito dentro-de-si, demarcando a noção de interioridade, não define mais o ser do sujeito de maneira absoluta, rompendo uma longa tradição iniciada no século XVI, isso implica em reconhecer que a oposição dentro-de-si e fora-de-si perde o poder simbólico de delinear os territórios e os limites entre o sujeito e o outro. Por isso mesmo, as noções de alteridade e de intersubjetividade se esvaziam e tendem ao silêncio na sociedade narcísica do espetáculo. Além disso, neste apagamento de fronteiras entre o dentro-de-si e o fora-de-si a idéia de temporalidade se esvai, entrando em colapso. A subjetividade tende a ganhar contornos espaciais, definindo-se por superfícies de contato e de superposição. Conseqüentemente as idéias de história e de temporalidade vão desaparecendo da racionalidade psicopatológica, sendo substituída pela noção de espaço. Enfim, a noção de memória se evapora progressivamente, num mundo subjetivo espacializado, onde a historicidade e a temporalidade não importam mais.

Pode-se depreender disso a perda de lugar das psicoses no discurso psicopatológico na atualidade, à medida que aquelas eram as representações paradigmáticas do sujeito fora-de-si. Por isso mesmo, as psicoses ocuparam o lugar privilegiado no discurso psiquiátrico desde as suas origens, até o final dos 


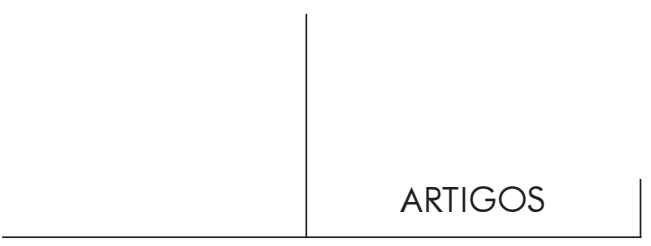

anos 70, porque polemizavam o estatuto do sujeito fora-de-si em oposição ao sujeito dentro-de-si. Em contrapartida, as perversões estão investidas de tudo a interesse possível, à medida que estas configuram a situação estratégica onde se apagam as fronteiras entre o sujeito dentro-de-si e o sujeito fora-de-si.

Enfim, o discurso psicopatológico da pós-modernidade recebe no seu corpo teórico este conjunto de transformações antropológicas que transformaram as maneiras de conceber o sujeito, subvertendo hierarquias e valores que marcaram a modernidade, como indicamos.

\section{Alquimias}

Dito tudo isso, pode surpreender quais as relações secretas que fundam a psicopatologia da pós-modernidade. É possível indicar agora as relações enigmáticas entre as depressões, as toxicomanias e a síndrome do pânico, que delineiam o campo clínico preferencial da nosografia funcional da psiquiatria na atualidade.

Assim, na cultura da exaltação desmesurada do eu não existe mais qualquer lugar para os deprimidos e os panicados. Esses são execrados, lançados no limbo da cena social, já que representam a impossibilidade de serem cidadãos da sociedade do espetáculo. Com efeito, a interiorização excessiva do depressivo, marcado pelas cavilações suspirosas, assim como o terror fóbio, que toma de corpo inteiro a individualidade panicada na cena pública, evidenciam como tais individualidades não conseguem realizar a tão esperada exaltação de si mesmo e se dedicar à artesania de seus figurinos maneiros para se mostrar com brilho na cena social.

A melancolia e o estilo sofredor de ser não estão mais na moda, definitivamente, como se passava ainda com as gerações existencialistas e beat, dos anos 40, 50 e 60. Da mesma forma, as pessoas com estilos mais retraído, reflexivo e sonhador não se coadunam mais com a ética vigente da exaltação do eu e do exibicionismo. A mundaneidade pós-moderna valoriza os carreiristas e os oportunistas, que sabem utilizar os meios de se exibirem e de capturarem o olhar dos outros, independente de qualquer outra coisa que esteja em jogo em termos de valores. Daí porque existe um certo conservadorismo político no universo pós-moderno, à medida que a modernidade sempre foi associada à ética da ruptura e da utopia em oposição ao exibicionismo barato.

Desta maneira, para os ferrados, que não conseguem dizer "cheguei", de peito inflado, a fórmula mágica é a alquimia, para mudar a circulação dos humores. É preciso dar uma pancada química na bílis negra, nos dizem os novos especialistas da alma sofrentes. Por este meio seria possível, acreditam aqueles, retirar as individualidades do cenário dark e inseri-las na cena colorida da 


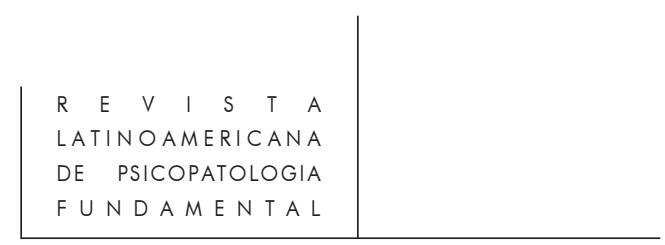

representação e do espetáculo. Como os humores são essências eternas e universais destituídas de história e de memória, basta a incidência de certas dosagens alquímicas para balançar a economia dos humores para outros pontos de equilíbrio. Enfim, o caldeirão científico da feiticeira pode tudo regular de maneira funcional e pontual, ajustando os desequilíbrios humorais.

Pelo hino cientificista, as toxicomanias são as prima Donna desta ópera burlesca, seja pelos psicofármacos supostamente medicamentosos, seja pelas ditas drogas pesadas, a química dos humores pretende instituir o élan exaltado e fascinante nos pobres coitados que não conseguem alçar o vôo e serem "bons" cidadãos da sociedade do espetáculo.

Estou afirmando com isso, que existe um processo de produção social das toxicomanias, pelas vias da medicalização psiquiátrica e do mercado de drogas pesadas, que encontra as suas condições de possibilidade na ética da sociedade do espetáculo e do narcisismo. É por isso que na seriação das grandes perturbações do espírito da pós-modernidade, as toxicomanias se inscrevem lado a lado com as depressões e a síndrome do pânico. Com efeito, se as alquimias científicas autorizadas pelas neurociências são os antídotos para as depressões e a síndrome do pânico, as toxicomanias são o desaguadouro necessário desta forma de intervenção terapêutica e de seus desdobramentos inequívocos na cena do social. Enfim, no estado de inebriamento tóxico as individualidades se sentem como cidadãos de direito da sociedade do espetáculo, nem que seja por um tempo limitado.

Na tragicomédia da cultura extasiante dos humores e dos brilharecos, a psicanálise entra inevitavelmente em crise, já que como saber sobre o desejo tem muito pouco a dizer sobre isso tudo, já que foi em face da exaltação inebriante do eu que aquela sempre se confrontou. Pretendendo realizar a desconstrução da majestade clownesca do eu, a psicanálise se funda numa ética que se choca com os pressupostos da ontologia do espetáculo. Como é que aquela vai sair desse imbróglio, se é que sairá inteira deste confronto de Titãs, já é um outro capítulo sobre o mal-estar na atualidade.

Paris, 5 de fevereiro de 1998.

\section{Resumos}

La intención de este estudio es la de circunscribir la especificidad de la psicoatología en la post-modernidad. Para eso busca demostrar las relaciones daquella con la medicina y las neurociencias, asi como su rechazo del psicoanálisis. Pretende, además, mostrar que el interes actual de la psiquiatria en las investigaciones sobre las depresiones, las toxicomanias y la sindrome del panico, puede ser interpretada a partir de los modelos de subjetividad promovidos por el mundo post-moderno. 


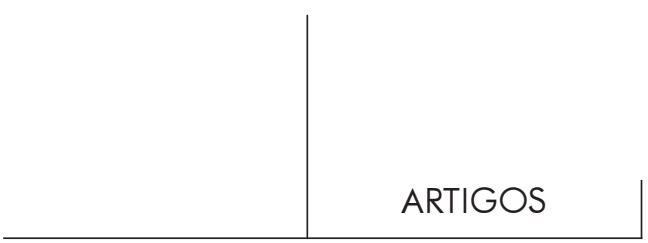

Il s'lagit de bien circonscrire le discours de la psychopathologie dans la postmodernité. On veut démontrer donc les rapports de celui-là avec la médecine et les neurosciences, ainsi que son refus de la psychanalyse. En outre, on veut montrer comment l'intêret acutel de la psychiatrie poar les recherches sur les dépressions, les toxicomanies et la syndrome du panique peut être interpreté selon les modèles de subjectivité remarqués dans le monde post-moderne.

The intention of this paper is to circunscribe the psychopatology in the postmodernity. To achieve that the author attemps to demonstrate the psychopatology relationship with the medicine and the neurosciences, as its repulse of the psychoanalysis. Besides that author intends to display how the nowadays interest of the psychiatry in the researches about the depressions, the toxicomanies and the panic syndron can be understood by the subject's models fostered by the post-moderne world. 